\section{Direito à saúde: um convite à reflexão}

\author{
Healthcare rights: an invitation for reflection
}

\section{Abstract}

This study focuses on changes and breaks in contemporary society relating to the right to healthcare as a universal value, in conformity with the guidelines provided by multilateral agencies and disseminated particularly since the 1990s. From the genesis of social rights and by tracing the interdependence between social and economic aspects of social citizenship in democratic capitalist countries, the study presents the two paradigms informing the approach to healthcare in the early $21^{\text {st }}$ century: the full citizenship paradigm, according to which the right to healthcare is a universal value, and the paradigm of restricted social citizenship, according to which the right to healthcare is guided by the criterion of efficiency and economic rationalization. These propositions align with the health economy paradigm, which (i) defends focused resource allocation to attenuate poverty conditions, (ii) reduces the role of the state, (iii) recommends resource allocation to healthcare in association with social protection, and (iv) defines the market as the privileged regulator of healthcare actions.

Rights to Health; Public Policy; Ethics
Vera Maria Ribeiro Nogueira 1

Denise Elvira Pires de Pires 2

\section{Introdução}

Este artigo contém uma reflexão sobre o direito à saúde enquanto um direito de cidadania social. Decorre de preocupações éticas e políticas que surgem e se intensificam em face das propostas para o setor saúde que vêm sendo veiculadas pelo Banco Mundial (BM), ou Banco Interamericano de Desenvolvimento e Organização Pan-Americana da Saúde (OPAS) 1,2 no início do século XXI. As propostas, ratificadas no Seminário Internacional: Tendências e Desafios dos Sistemas de Saúde das Américas, promovido pelo Ministério da Saúde, em agosto de 2002, acentuam as indicações da primeira geração das reformas sanitárias na América Latina. As reformas da primeira geração foram analisadas de forma competente por Almeida 3,4,5,6,7, Costa et al. 8, Carvalheiro 9, Londoño \& Frenk 10, Melo \& Costa 11, Ugalde \& Jackson 12 e Laurell $13,14,15$, entre outros. Os esforços investigativos permitiram reconhecer os pressupostos ideológicos, políticos, sociais e econômicos que orientam as propostas de transformações do setor saúde no final do século XX.

A nova agenda, denominada pelas agências multilaterais como a segunda geração das reformas sanitárias 2 (Laforgia J, Raw S, Levcovitz E, comunicação pessoal), vem complementar as reformas de primeira geração, concluídas na década de 90. Suas primeiras formulações partem do discurso do presidente do BM, Wolfen- 
sohn 16, em 06 de outubro de 1998, com forte apelo à articulação entre pobreza e a atenção à saúde, sugerindo a necessária focalização de recursos para atenuar as condições de miserabilidade e melhorar a qualidade de vida da população empobrecida.

Frente a esse quadro é importante pensar os significados que estão sendo atribuídos crescentemente ao direito à saúde, em um cenário em que os arranjos entre o setor público e o setor privado nem sempre são pautados em uma racionalidade ética inclusiva, onde a miserabilidade e as situações denominadas de vulnerabilidade social definem o objeto privilegiado das políticas sociais. Observa-se o reenquadramento da sociedade civil como parceira do poder público, perdendo esta seu papel político de controle social e "identificando-se a naturalização da desigualdade", conforme mencionado por Esping-Andersen 17 (p. 20).

A retomada do debate ao articular direito à saúde e reformas sanitárias pode contribuir para iluminar ações que, a médio e longo prazos, possam reverter o cenário atual. Nesse sentido, o texto pretende rever as visões teórico-políticas sobre o direito à saúde destacando a sua paulatina fragilização diante das atuais propostas de reforma sanitária de segunda geração.

\section{A gênese do direito à saúde}

Analisando as políticas sociais setoriais, especialmente as de saúde, Bayer \& Leys 18 situamnas em um duplo contexto, na relação direta entre capital e trabalho, e como uma questão referenciada aos aspectos políticos. Suas contribuições constituem um arcabouço sugestivo para a abordagem do direito à saúde, ultrapassando análises conjunturais, tecnocráticas, ou ainda, desvinculadas das condições sócio-históricas.

Os autores sugerem que para se entender a constituição das políticas setoriais deve-se retomar, brevemente, as atribuições e papéis do Estado democrático de direito em países capitalistas, em decorrência de sua expansão e ampliação de funções no pós-Segunda Guerra. Nesse sentido, destacam três encaminhamentos políticos adotados nas democracias capitalistas ocidentais: (1) o Estado antecipa-se às necessidades de expansão do processo de acumulação capitalista; (2) o Estado assume como função sua o desenvolvimento de atividades próprias do setor privado e (3) utiliza a setorialização da política como mecanismo de fragmentação da participação social, dificultando, assim, as oportunidades de aglutinação de in- teresses coletivos e mais universais. Os mesmos autores reconhecem, ainda, que as relações sociais não ocorrem no abstrato, ou entre as pessoas individualmente, mas são "mediadas por um complexo esquema institucional, coordenado pelo Estado, com conseqüências tanto para a dimensão da produção, como para o plano das práticas políticas" 18 (p. 115).

Uma primeira conseqüência é, no welfare state social, o provimento crescente de atividades ligadas à esfera da reprodução das condições de vida da população, sob a responsabilidade pública, desvinculando-as, aparentemente, da relação direta entre o capital e o trabalho, conferindo uma aparente neutralidade ao papel estatal e independentizando-o da esfera da produção 19. Pode-se afirmar que esse encaminhamento viabiliza o isolamento do Estado da dinâmica societária e naturaliza as exigências da vida cotidiana, que são interpretadas de per si e não conectadas ao setor econômico. Nesse processo, as intervenções na esfera das políticas sociais como que se autonomizam da esfera da produção, situando-se como um mundo à parte, podendo as suas falhas e suas inconsistências serem explicadas como incompetência do Estado. E o que é mais sério, tais ações podem ser atribuídas, ainda, a um sentimento humanista e beneficente, a um problema da esfera administrativa ou, quando muito, relacionadas aos aspectos unicamente redistributivos.

Uma segunda conseqüência é a tendência de concentração da participação política da população em aspectos setoriais, fragmentando tanto a densidade participativa, como dificultando a avaliação da legitimidade do Estado e de sua pretensa neutralidade.

"Paralelamente, o argumento da condução dessas políticas não é diretamente político, mas sim técnico e aparentemente específico a cada área de política. Com isso, a questão da legitimação transforma-se em um somatório de argumentações técnicas específicas, reduzindo-a, portanto, a uma questão de eficiência" 18 (p. 117)

Bayer \& Leys 18 alertam ainda, para o potencial de controle exercido por meio das políticas de saúde sobre a classe trabalhadora. Nesse campo, cabe retomar a posição de Offe 20 , ao analisar o papel das políticas de proteção ao trabalho. Entende o autor, que as políticas sociais favoreceram a transformação de mão-deobra não-assalariada em assalariada, na medida em que oferecem ao trabalhador uma segurança futura em troca de seu ingresso no mercado de trabalho. 


\section{Direito social e cidadania revisitados: relações com o campo polí- tico e econômico}

A opção teórica sobre direito social e cidadania que sedimenta esta reflexão, indica que ambos devem ser apreendidos como vinculados a uma cidadania ativa, como uma constante luta contra qualquer constrangimento que impeça o seu exercício ou, como sugere Oliveira 21, a garantia de uma autonomia plena nas dimensões civis, políticas e sociais. Essa autonomia não ocorre em um vazio, ou em um espaço virtual, conforme colocado na teoria jurídica clássica, mas em situações cotidianas e reais de existência.

Os direitos sociais não devem ser entendidos como uma ficção jurídica, o que favorece o obscurecimento das críticas sobre sua não-garantia, reduzindo seu potencial político de transformação da ordem societária. É preciso afastar-se da visão de um ideal de direito social que não se realiza no plano concreto. É preciso considerar a universalidade e a igualdade em sua expressão plena, evidenciando as formas de relações sociais estabelecidas e transitando entre o plano dos valores e da materialidade efetiva. É preciso, portanto, deslocar-se de uma perspectiva formalista e alcançar a realização cotidiana, somente possível em espaços públicos onde os interesses divergentes são traduzidos, democraticamente, em consensos relativos que devem ser objetivados em práticas concretas.

Contrariando a abordagem clássica dos fenômenos jurídicos, entre os quais se inscrevem os direitos sociais, entende-se que as condições legais, ou formas políticas, não se explicam por si mesmas como pretendem os defensores dos procedimentos essencialmente normativos, que difundem uma idéia de justiça autonomizada das condições objetivas, independente dos modos de organização da produção e reprodução social. Qualquer análise sobre instituições no plano do direito implica articular a cidadania social às condições reais de existência, tendo como pressuposto as relações econômicas e sociais que condicionam, no limite, os fenômenos jurídicos e políticos 22,23,24,25.

Tendo como base as premissas acima, novos aportes vêm sendo incluídos na discussão sobre os direitos sociais, mormente aqueles que os apreendem como aglutinando interesses e favorecendo a abertura de instâncias de confrontos e negociações entre o Estado, o capital e o trabalho. Foi se constituindo um novo olhar sobre os direitos, especialmente os sociais, deslocando-os de uma perspectiva for- malista, não-histórica, para assentá-los nas condições reais de existência, particularizados em cada formação social. Podem ser considerados, portanto, no plano político, como uma das instâncias de lutas coletivas, tendo como palavra de ordem o direito a ter direitos, consoante à indicação de Telles 23 . A cidadania social contém, assim, uma densidade que é afirmada e reconhecida na concretude das relações sócio-históricas, espraiando-se para os distintos setores e áreas da vida.

A partir da década de 70, a crise do Estado de Bem-Estar e os processos de transformação no campo da produção e revisão do papel do Estado, tornam quase obrigatório abordar o direito à saúde na sua relação com o fundo público. A apropriação, pelos agentes econômicos, dos recursos orçamentários na atenção à saúde vem sendo qualificada como mercantilização da saúde, no sentido que "o setor privado de bens e prestação de serviços de saúde ganha autonomia no que diz respeito às suas condições de financiamento, ao mesmo tempo em que o Estado desenvolve um novo aparato regulatório para o desenvolvimento do setor" 26 ( $\mathrm{p}$. 17). Tal processo ratifica a argumentação de que os direitos sociais estão intrinsecamente relacionados à dimensão econômica.

Nessa linha de raciocínio, a contribuição de Oliveira 27 é significativa, pois permite apreender os nexos entre as dimensões políticas e econômicas no universo da saúde, que sempre foi colocada em um patamar diferenciado, mais referenciado aos ideais de solidariedade e benemerência e não de mercadoria. Este autor, sistematicamente, vem discutindo o papel do fundo público e sua conseqüente relação com a esfera pública, a democracia e as políticas sociais. Contrariamente ao que ocorria no capitalismo concorrencial, quando o fundo público possuía um caráter ex-post, ou seja, surgia em seguida ao ciclo de reprodução do capital, hoje, o fundo público ocupa uma posição ex-ante das condições de reprodução dos capitais particulares e das condições de reprodução da vida social.

A resultante desse percurso instituiu uma esfera pública, ou uma economia de mercado socialmente regulada, nos marcos da democracia contemporânea, alterando o paradigma liberal clássico. Oliveira 27 ressalta que o Estado de Bem-Estar continua a ser um Estado classista, e usando a metáfora do jogo de xadrez, explica que "este se transformou em um espaço de luta onde as regras são previamente hierarquizadas podendo, no entanto, mudar a relação de forças entre valores assimétricos" 27 (p. 23). Defende que a "forma política mais adequada pa- 
ra construção da esfera pública é o espaço da democracia representativa" 27 (p. 23).

Para além do plano econômico, no plano político, a qualidade e o tipo da representação ampliaram sobremaneira o papel dos partidos políticos, que passam a não ser mais unicamente identificados com as classes sociais, como o foram originariamente, mas como representantes de classes, com competência para processar as novas formas de relações de alteridade que se fazem presentes no jogo democrático. Essas relações e o jogo de interesses presentes, relacionam-se em uma perspectiva de resultados e não apenas de pressupostos, o que exige uma capacidade de articulação de interesses e não mais a imposição da vontade geral em termos rousseaunianos, destacando-se a relevância das classes médias nessa interpolação de conflitos 28 . A saúde passou a fazer parte da busca desse resultado, que interessa, indistintamente, à reprodução do capital e da força de trabalho, sendo que a busca de investimentos na garantia e expansão dos direitos nessa área, aglutina interesses que se transformam em forças políticas.

A estreita relação entre o direito à saúde e o fundo público, especialmente nos países capitalistas desenvolvidos a partir dos anos 70, mostra que o potencial das ações e serviços de saúde ultrapassa o papel de regulação política da força de trabalho, sendo, também, uma atividade potencial e crescentemente lucrativa que envolve diversos setores produtivos, desde os produtores de insumos e pesquisas até as intervenções, via atendimento médico e hospitalar à população.

Os modelos que possuíam como fundamento de aglutinação e sustentação o ideal de solidariedade social e justiça estão sendo rapidamente superados pelo chamado "Consenso de Mercantilização da Saúde”, nas palavras de Braga \& Silva 29 (p. 21). Os imperativos macroeconômicos e as estratégias mercadológicas, utilizados em larga escala, têm contribuído para transformar a saúde em um objeto corriqueiro de consumo e para realizar uma metamorfose na concepção de direito à saúde 14,15. A confirmação desse fato é ser a área da saúde, nos dias atuais, o setor terciário da economia que mais cresce, com significativa relevância no processo de acumulação do capital e destacando-se pelo seu dinamismo e importância 9,30.

\section{O campo jurídico no debate do direito à saúde}

Na perspectiva das instituições e respectivas mediações, os direitos sociais, e especialmente o direito à saúde, se relaciona à teoria do direito. Direito entendido em dois sentidos atribuídos por Dallari \& Fortes 31 (p. 188), apoiandose em Reale: "o direito, um sistema de normas que regulamenta o comportamento dos homens em sociedade. Muitas vezes se emprega o direito em um sentido axiológico, como sinônimo de justiça, e muitas outras em sentido subjetivo. [...] Na reivindicação do direito à saúde, o termo é empregado em seu sentido subjetivo. Todavia, a referência a regras de direito, vista por dentro, implica necessariamente a compreensão do direito como regras do comportamento humano em sociedade".

Ainda que o argumento tenha uma carga normativa bastante acentuada, não se pode desconhecer sua importância, pois influencia, positivamente, as deliberações a respeito da responsabilidade de cada um e do Estado em sua garantia.

Esses autores reconhecem, na esteira de outros estudiosos que relacionam o direito à saúde ao desenvolvimento do sistema capitalista de produção, que foi a urbanização e o processo de industrialização, com suas conseqüentes manifestações de ordem política que impuseram ao Estado, o provimento das ações de saúde, especificamente em saneamento e nos códigos sanitários.

Ainda no plano jurídico, outra distinção é a contraposição entre o direito individual e o coletivo. No plano individual, a garantia do direito à saúde envolve a liberdade em várias situações, como por exemplo, o tipo de tratamento, a relação com o meio ambiente e as condições de trabalho. A liberdade individual, assim, implicaria escolhas entre distintas e alternativas.

No plano social, o direito à saúde pode ser avaliado em duas vertentes: na primeira, as exigências aos indivíduos face às necessidades coletivas, que é o que os obriga a submeterem-se às normas jurídicas, como à vacinação, ao tratamento, ao isolamento em casos de algumas doenças infecto-contagiosas, à destruição de produtos impróprios para o consumo, ao controle do meio ambiente e do ambiente de trabalho; e, a segunda, diz respeito à garantia da oferta de cuidados da saúde a todos que deles necessitam, o que corresponde ao ideal de igualdade, e que, por sua vez, se submete ao pleno desenvolvimento do Estado democrático de direito.

Dallari \& Fortes 31 chamam a atenção para a tensão entre liberdade e igualdade ao se tra- 
tar do direito à saúde. Na esfera jurídica, esse direito, ao apropriar-se da liberdade e da igualdade "caracteriza-se pelo equilíbrio instável desses valores. [...]. Os homens sempre tiveram a consciência de que para nada serve a igualdade sob o jugo do tirano e a liberdade só existe entre iguais" 31 (p. 190).

Embora esclareçam aspectos essenciais, a argumentação acima deve, forçosamente, incluir a relação Estado-sociedade-indivíduo. Mesmo que o individualismo permaneça como principal característica dos direitos humanos, enquanto direitos subjetivos, as opções políticas de cada sociedade diferenciam os papéis assumidos pelo Estado. Em outros termos, nas sociedades liberais o papel estatal se distingue, nitidamente, do papel do indivíduo, havendo sempre a preocupação em resguardar os direitos desse frente ao Estado. Como conseqüência, sua interferência se resume na garantia dos direitos negativos, na preservação da ordem, das leis e, no plano da saúde, quando muito, na saúde pública. Em sociedades de perfil socialista, social-democrata ou mesmo com tendências mais progressistas politicamente, há o reconhecimento, no plano da lei, de direitos de titularidade coletiva. Nesses casos, há a interferência estatal em aspectos condizentes, inclusive aos direitos individuais, e a indicação da igualdade da cidadania face às questões sanitárias.

\section{Os paradigmas relativos à atenção à saúde e as reformas sanitárias}

A crise econômica ocorrida nos países do Ocidente desenvolvido, provocada pela redução nas taxas de acumulação do capital, levou ao esgotamento do pacto keynesiano que perdurou do pós-Segunda Guerra até fins dos anos 60, e imprimiu novos arranjos no capitalismo internacional com conseqüências já reconhecidas na área das políticas de proteção social e saúde 11,32,33,34,35.

Nesse sentido, a influência do BM na determinação das políticas de saúde nacionais e sua expansão como matriz hegemônica internacional na área, vêm sendo objeto de estudos recentes, entre os quais se destacam os de Laurell 13,15, Lima 36, Marques \& Mendes 37, Rocha 38, Rizzotto 34 e Melo \& Costa 11. Vários autores assinalam, ainda, que o BM não é a única agência multilateral que vem influenciando a agenda das reformas estruturais na América Latina, e, na saúde, apontando para a oportunidade de um sistema misto e plural de atenção sanitária. A estratégia proposta leva a uma alteração do paradigma teórico de atenção à saúde e esta mudança vem sendo objeto de reflexão desde a década de 90, sendo que a contribuição de Melo \& Costa 11 é significativa nesse debate.

Hoje, são identificados dois paradigmas teórico-políticos em relação ao direito à saúde. De um lado, o paradigma da saúde pública, defendido pelas tradicionais agências de atenção à saúde e, de outro, o da economia da saúde. $\mathrm{O}$ primeiro "adota o princípio da eqüidade e o marco conceitual da epidemiologia [...]", e o segundo, adota "o paradigma da economia da saúde, os princípios da competitividade, da focalização e seletividade da ação pública, e o método das ciências econômicas e administrativas" 9 (p. 9).

Consoante Marques \& Mendes 37 na década de 90, a OPAS inicia a defesa da redefinição do papel do Estado em busca do crescimento e da eqüidade para a América Latina e defendia "embora de forma cautelosa, que os individuos e as famílias de maior renda contribuíssem no financiamento da saúde" 37 (p. 274), o que liberaria recursos estatais para a cobertura de uma cesta básica de atenção à saúde. Concorda-se com Marques \& Mendes 39, que a OPAS estaria, em nome da universalidade da atenção básica, ferindo o principio da integralidade e universalidade enquanto um direito de todos ao reduzi-lo aos segmentos populacionais empobrecidos.

Efetivamente, em 1994, a Comissão Econômica para América Latina e Caribe (CEPAL), juntamente com a OPAS, formula um documento associando reestruturação produtiva, saúde e eqüidade, acentuando o papel do Estado como coordenador do processo de desenvolvimento e defendendo a conveniência da parceria entre o setor público e o privado no campo da saúde 40. A decisão de mobilizar os recursos do setor privado, além das organizações nãogovernamentais, aconteceu na assembléia da Organização Mundial da Saúde (OMS), em 1993 41. O novo posicionamento pode ser identificado, entre outros autores, em Marques \& Mendes 37, Buse \& Waxman 41, além do Editorial da Revista Panamericana de Salud Pública 1.

\section{Conclusão}

Ainda que a segunda geração das reformas em saúde propostas pelas agências multilaterais, mencionadas no início do texto, esteja em fase de implementação, as pontuações dos dirigentes institucionais permitem afirmar que está em curso, na definição da atenção pública à saúde, uma acentuação da focalização e na se- 
letividade pautada na pobreza. A nova agenda para o século XXI engloba proposições derivadas do paradigma da economia da saúde, acentuando fortemente uma visão de cidadania social restrita, dirigida aos segmentos populacionais extremamente empobrecidos e articulando atenção à saúde com proteção social.

As exigências de ordem econômica e política vão conformando o direito à saúde, alterando seu conteúdo, seu alcance e os mecanismos acionados para sua garantia, tanto nos países entre si, como, muitas vezes, no interior de cada país. As tendências recentes de ajustes estruturais $35,38,42$ nos países capitalistas de economia periférica ampliam essa complexidade e diversidade.

O direito à saúde, ao ser analisado numa perspectiva sociohistórica, deixa de ser visto como uma decorrência dos ideais humanitários de solidariedade, de moralidade ética, de justiça social e de necessidade básica articulada à sobrevivência, e passa a ser visto como uma exigência dos processos de acumulação de capital e subordinado aos complexos e intrincados mecanismos de mediação, próprios do sistema capitalista em seu estágio atual.

Inicialmente, no que diz respeito ao paradigma teórico de atenção à saúde, a OMS, suas agências regionais e o BM, pareciam estar em campos opostos, no entanto, o que vem se constatando hoje é que há uma única direção

\section{Resumo}

As alterações e rupturas que vêm ocorrendo na sociedade contemporânea em relação ao direito à saúde como valor universal, consoantes às orientações das agências multilaterais veiculadas especialmente a partir dos anos 90, constitui-se o foco central do presente estudo. A partir da gênese dos direitos sociais e do resgate da interdependência entre os aspectos sociais e econômicos na conformação da cidadania social nos países capitalistas democráticos, apresenta os dois paradigmas que delimitam o encaminhamento da atenção à saúde no início do século XXI. O paradigma da cidadania plena, no qual o direito à saúde é um valor universal, e o da cidadania social restrita, em que o direito à saúde é orientado pelo critério da eficiência e racionalidade econômica. Essas proposições alinham-se ao paradigma da economia da saúde, que defende a focalização dos recursos para atenuar as condições de miserabilidade, reduz o papel do Estado, sugere a alocação de recursos para a saúde aliada à proteção social e coloca o mercado como o regulador privilegiado das ações de saúde.

Direito à Saúde; Política Social; Ética política, a qual é difundida nas distintas frentes de ação desses organismos conforme analisam Mattos 42 e Marques \& Mendes 37 . Vem ocorrendo uma mudança na hegemonia do paradigma da eqüidade em saúde, que vinha sendo defendida pela OMS e suas agências regionais, em direção a um paradigma de eqüidade em saúde com focalização. Esta mudança indica que a apreensão do direito à saúde, desde um ideal de igualdade e eqüidade em saúde, está mudando para um entendimento que o direito social à saúde incorpora outros critérios distributivos, nomeadamente o da situação de pobreza e vulnerabilidade social. A forma de financiamento e operacionalização das políticas sanitárias aponta para a articulação públicoprivado, eximindo-se o Estado de seu papel de garantidor de direitos.

O texto procurou mostrar, também, que o direito à saúde é um item complexo da agenda política e da agenda governamental, e que o debate, ou seja, o confronto sobre seu alcance e seu conteúdo é fundamental. Os interesses presentes e a capacidade organizativa dos diferentes grupos que compõem o setor darão o tom do debate e, mais do que isso, viabilizarão a inclusão e efetivação do direito à saúde com um perfil onde a democracia e a universalidade encontrarão abrigo amplo ou serão extremamente reduzidas.

\section{Colaboradores}

V. M. R. Nogueira contribuiu na elaboração do texto inicial e provisório. D. E. P. Pires colaborou nas revisões refeitas com base na solicitação dos consultores. 


\section{Referências}

1. Organização Pan-Americana da Saúde. Rev Panam Salud Pública 2000; 8:1-2.

2. Marin JM. Seminário internacional tendências e desafios dos sistemas de saúde das Américas. São Paulo: Ministério da Saúde; 2002.

3. Almeida C. Crise econômica, crise do Welfare State e reforma sanitária. In: Gerschman S, Werneck ML, organizadores. A miragem da pós-modernidade: democracia e política no contexto da globalização. Rio de Janeiro: Editora Fiocruz; 1997. p. 177-200.

4. Almeida C. Gestão da saúde no contexto da reforma do estado. In: Brasil. Ministério da Saúde. Regulação e gestão de recursos humanos em saúde na perspectiva da reforma do Estado - relatório final. Brasília: Ministério da Saúde; 1998. p. 99-114.

5. Almeida C. Saúde nas reformas contemporâneas. In: Costa AM, Merchán-Hamann E, Tajer D, organizadores. Saúde, eqüidade e gênero: um desafio para as políticas públicas. Brasília: Universidade de Brasília/ABRASCO/ALAMES; 2000. p. 61-93.

6. Almeida C. Eqüidade e reforma setorial na América Latina: um debate necessário. Cad Saúde Pública 2002; 18:23-36.

7. Almeida C. Reforma de sistemas de servicios de salud y equidad en América Latina y el Caribe: algunas lecciones de los años 80 y 90. Cad Saúde Pública 2002; 18:905-25.

8. Costa NR, Silva PL, Ribeiro JM. Inovações organizacionais e de financiamento: experiências a partir do cenário institucional. In: Negri B, Di Giovanni G, organizadores. Brasil: radiografia da saúde. Campinas: Instituto de Economia, Universidade Estadual de Campinas; 2001. p. 291-306.

9. Carvalheiro JR. Os desafios para a saúde. Estudos Avançados 2000; 35:7-10.

10. Londoño JL, Frenk J. Pluralismo estruturado: hacia un modelo inovador para la reforma de los sistemas de salud en America Latina. Banco Interamericano de Desarrollo. Washington, DC: Banco Interamericano de Desarrollo, Oficina del Economista Jefe; 1997. (Documento de Trabajo, n. 353).

11. Melo MA, Costa NR. Desenvolvimento sustentável, ajuste estrutural e política social: as estratégias da OMS/OPS e do Banco Mundial para a atenção à saúde. Planej Polit Públicas 1994; 11:49-108.

12. Ugalde A, Jackson JT. Las políticas de salud del Banco Mundial: una revisión crítica. Cuad Méd Soc (Santiago) 1998; 73:45-60.

13. Laurell AC. La lógica de la privatizacion en salud. In: Eibenschutz C, organizador. Política de saúde: o público e o privado. Rio de Janeiro: Editora Fiocruz; 1995. p. 31-48.

14. Laurell AC. Globalización y reforma del estado. In: Costa AM, Merchán-Hamann E, Tajer D, organizadores. Saúde, eqüidade e gênero: um desafio para as políticas públicas. Brasília: Universidade de Brasília/ABRASCO/ALAMES; 2000. p. 35-60.

15. Laurell AC. La salud: de derecho social a mercancia. Boletín APS 2000; 5:81-92.

16. Wolfensohn JD. The other crisis. Washington DC: Banco Mundial; 1998.

17. Esping-Andersen G. Fundamentos sociales de las economías postindustriales. Barcelona: Editora Ariel; 2000.
18. Bayer GF, Leys HR. Saúde enquanto questão politicamente intermediada. Serviço Social e Sociedade $1986 ; 22: 108-25$.

19. Castells M. Crise do estado, consumo coletivo e contradições urbanas. In: Poulantzas N, organizador. A crise do estado. Lisboa: Editora Moraes; 1978. p. $145-70$

20. Offe C. Problemas estruturais do estado capitalista. Rio de Janeiro: Editora Tempo Brasileiro; 1984.

21. Oliveira F. O que é formação para a cidadania? http://www.dhnet.org.br/textos/coliveira.htm (acessado em 14/Mai/2002).

22. Bobbio, N. A era dos direitos. Rio de Janeiro: Editora Campus; 1992.

23. Telles VS. Pobreza, movimentos sociais e cultura política: notas sobre as difíceis relações entre pobreza, direitos e democracia. In: Diniz E, Lopes JSL, Prandi R, organizadores. O Brasil no rastro da crise. São Paulo: Editora Anpocs/Hucitec/Instituto de Pesquisa Econômica Aplicada;1994. p. 225-43.

24. Martínez De Pisón J. Políticas del bienestar: un estúdio sobre los derechos sociales. Madri: Tecnos; 1998.

25. Dagnino E. Sociedade civil e espaços públicos no Brasil. São Paulo: Editora Paz e Terra; 2002.

26. Negri B, Di Giovanni G. Brasil: radiografia da saúde. Campinas: Instituto de Economia, Universidade Estadual de Campinas; 2001.

27. Oliveira F. O surgimento do antivalor. Novos Estudos Cebrap 1988; 22:8-28.

28. Esping-Andersen G. The three worlds of welfare capitalism. Princeton: Princeton University Press; 1998.

29. Braga JCS, Silva PLB. A mercantilização possível e as políticas públicas inadiáveis: estrutura e dinâmica do setor saúde no Brasil. In: Negri B, Di Giovanni $G$, organizadores. Brasil: radiografia da saúde. Campinas: Instituto de Economia, Universidade Estadual de Campinas; 2001. p. 19-42.

30. Pires D. Reestruturação produtiva e trabalho em saúde no Brasil. São Paulo: Editora Annablume; 1998.

31. Dallari SG, Fortes PAC. Direito sanitário: inovação teórica e novo campo de trabalho. In: Fleury S, organizador. Saúde e democracia: a luta do CEBES. São Paulo: Editora Lemos; 1997. p. 187-202.

32. Costa NR, Ribeiro JM. Reforma do estado, reforma administrativa e impacto na gestão em saúde. http://ead.fiocruz.br/cursos/autogestao/ags/apre sentacao/autogestao/contexto/tema3/tema3_c. html (acessado em 15/Mai/2002).

33. Iriart C, Merhy EE, Waitzkin H. La atención gerenciada en América Latina. Transnacionalización del sector salud en el contexto de la reforma. Cad Saúde Pública 2000; 16:95-105.

34. Rizzotto MLF. O Banco Mundial e as políticas de saúde no Brasil nos anos 90: um projeto de desmonte do SUS [Tese de Doutorado]. Campinas: Faculdade de Ciências Médicas, Universidade Estadual de Campinas; 2000.

35. Soares LTR. Ajuste neoliberal e desajuste social na América Latina. Rio de Janeiro: Universidade Federal do Rio de Janeiro; 1999.

36. Lima CRM. Reforma do estado e políticas de saú- 
de: discussão da agenda do Banco Mundial e da crítica de Laurell. Saúde em Debate 1996; 49/50: 34-43.

37. Marques RM, Mendes A. Estado e saúde: a posição das agências internacionais e a experiência brasileira recente. Indicadores Econômicos - FEE 2002; 29:272-89.

38. Rocha PM. Banco Mundial e saúde: a marcha liberal dos anos 90. Rio de Janeiro: Instituto de Medicina Social, Universidade do Estado do Rio de Janeiro; 1999. (Série Estudos em Saúde Coletiva, texto 196).

39. Marques RM, Mendes A. O SUS e a atenção básica: a busca de um novo desenho. Base de dados CEDOC. http://www.opas.org/htm/textos (acessado em 10/Mai/2002).
40. Comissão Econômica para a América Latina e Caribe, Organização Pan-Americana de Saúde. Salud, equidad y transformación productiva en America Latina y el Caribe. Washington, DC: Organização Pan-Americana de Saúde; 1994. (Serie Documentos Reproducidos).

41. Buse K, Waxman A. Public-private health partnership: a strategy for WHO. Bull World Health Org 2001; 79:748-54.

42. Mattos RA. As agências internacionais e as políticas de saúde nos anos 90: um panorama geral da oferta de idéias. Ciênc e Saúde Coletiva 2001; 6: 377-89.

Recebido em 30/Dez/2002

Versão final reapresentada em 17/Out/2003 Aprovado em 30/Out/2003 